\title{
Phase I Study of Ipilimumab Combined with Whole Brain Radiation Therapy or Radiosurgery for Melanoma Patients with
} Brain Metastases

\author{
Noelle L. Williams \\ Thomas Jefferson University \\ Evan J. Wuthrick \\ Ohio State University \\ Hyun Kim, MD \\ Thomas Jefferson University \\ Joshua D. Palmer

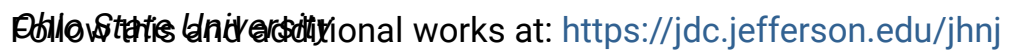 \\ betheng know how access to this document benefits you
} Thomas Jefferson University

\section{Recommended Citation}

Williams Noelle L.: Wuthrick, Evan J; Kim, MD, Hyun; Palmer, Joshua D.; Garg, Shivank; Eldredge-Hindy, Harriet B.; Daskalakis, Constantine; Feeney, Kendra J.; Mastrangelo, Michael; Kim, Lyndon; Sato, Takami; Olencki, Thomas; Liebner, David A.; Farrell, MD, Christopher J; Evans, James J.; Judy, MD, Kevin; Andrews MD, David W.; Dicker, Adam MD, PhD; Werner-Wasik, Maria; Shi, Wenyin; and Kendra, Kari L. (2018) "Phase I Study of Ipilimumab Combined with Whole Brain Radiation Therapy or Radiosurgery for Melanoma Patients with Brain Metastases," JHN Journal: Vol. 13 : Iss. 1 , Article 3.

DOI: https://doi.org/10.29046/JHNJ.013.1.003

Available at: https://jdc.jefferson.edu/jhnj/vol13/iss1/3

This Article is brought to you for free and open access by the Jefferson Digital Commons. The Jefferson Digital Commons is a service of Thomas Jefferson University's Center for Teaching and Learning (CTL). The Commons is a showcase for Jefferson books and journals, peer-reviewed scholarly publications, unique historical collections from the University archives, and teaching tools. The Jefferson Digital Commons allows researchers and interested readers anywhere in the world to learn about and keep up to date with Jefferson scholarship. This article has been accepted for inclusion in JHN Journal by an authorized administrator of the Jefferson Digital Commons. For more information, please contact: JeffersonDigitalCommons@jefferson.edu. 


\section{Phase I Study of Ipilimumab Combined with Whole Brain Radiation Therapy or Radiosurgery for Melanoma Patients with Brain Metastases}

\section{Authors}

Noelle L. Williams; Evan J. Wuthrick; Hyun Kim, MD; Joshua D. Palmer; Shivank Garg; Harriet B. EldredgeHindy; Constantine Daskalakis; Kendra J. Feeney; Michael Mastrangelo; Lyndon Kim; Takami Sato; Thomas Olencki; David A. Liebner; Christopher J Farrell, MD; James J. Evans; Kevin Judy, MD; David W. Andrews MD; Adam Dicker MD, PhD; Maria Werner-Wasik; Wenyin Shi; and Kari L. Kendra 


\section{Phase I Study of Ipilimumab Combined with Whole Brain Radiation Therapy or Radiosurgery for Melanoma Patients with Brain Metastases}

Noelle L. Williams, MD'; Evan J. Wuthrick, MD²; Hyun Kim, MD'; Joshua D. Palmer, MD²; Shivank Garg, MD; Harriet B. Eldredge-Hindy, MD³; Constantine Daskalakis, $\mathrm{SCD}^{4}$, Kendra J. Feeney, MD5 ; Michael J. Mastrangelo, $\mathrm{MD}^{5}$; Lyndon J. Kim, $\mathrm{MD}^{5}$; Takami Sato, MD, PhD5; Kari L. Kendra, MD; ; Thomas Olencki, DO6; David A. Liebner, MD6\% Christopher J. Farrell, MD7; James J. Evans, MD7, Kevin D. Judy, MD7; David W. Andrews, MD7; Adam P. Dicker, MD¹; Maria Werner-Wasik, MD; Wenyin Shi, MD ${ }^{1}$

1Department of Radiation Oncology, Thomas Jefferson University, Sidney Kimmel Cancer Center at Jefferson, Philadelphia, PA.

2Department of Radiation Oncology, Ohio State University, Columbus, $\mathrm{OH}$.

${ }^{3}$ Department of Radiation Oncology, Baystate Medical Center, Springfield, MA.

${ }^{4}$ Department of Biostatistics, Thomas Jefferson University, Philadelphia, PA.

${ }^{5}$ Department of Medical Oncology, Thomas Jefferson University and Sidney Kimmel

Cancer Center, Philadelphia, PA.

${ }^{6}$ Division of Medical Oncology, Ohio State University, Columbus, $\mathrm{OH}$.

'Department of Neurosurgery, Thomas Jefferson University and Sidney Kimmel Cancer Center, Philadelphia, PA

\section{Running Title}

Ipilimumab with RT for Melanoma Brain Metastases

\section{Funding sponsor}

Bristol-Myers Squibb

\section{Conflict of interest}

none

\section{Key Words}

immunotherapy, ipilimumab, metastatic melanoma, brain metastases

\begin{abstract}
Purpose: We performed a phase I study to determine the maximum tolerable dose (MTD) and safety of ipilimumab with stereotactic radiosurgery (SRS) or whole brain radiotherapy (WBRT) in patients with brain metastases (BM) from melanoma.

Methods: Based on intracranial (IC) disease burden, patients were treated with WBRT (Arm A) or SRS (Arm B). Ipilimumab starting dose was 3 mg/kg (every 3 weeks, starting on day 3 of WBRT or 2 days after SRS). Ipilimumab was escalated to $10 \mathrm{mg} / \mathrm{kg}$ using a two-stage, $3+3$ design. The primary endpoint was to determine the MTD of ipilimumab combined with radiotherapy. Secondary endpoints were overall survival (OS), IC and extracranial (EC) control, progression free survival (PFS), and toxicity. This trial is registered with ClinicalTrials.gov, number NCT01703507.
\end{abstract}

Results: Characteristics of the 16 patients enrolled between 2011 and 2014 were: mean age, 60; median BM, 2 (1 to >10); number with EC disease, 13 (81\%). Treatment included $\operatorname{WBRT}(n=5), \operatorname{SRS}(n=11)$, ipilimumab $3 \mathrm{mg} / \mathrm{kg}(n=7), 10 \mathrm{mg} / \mathrm{kg}(n=9)$. Median follow-up was 8 months (Arm A) and 10.5 months (Arm B). There were 21 grade 1-2 neurotoxic effects with no dose-limiting toxicities (DLTs). One patient experienced grade 3 neurotoxicity prior to ipilimumab administration. Ten additional grade 3 toxicities were reported with gastrointestinal $(n=5,31 \%)$ as the most common. There were no grade $4 / 5$ toxicities. Median PFS and OS, respectively, in Arm A were 2.5 months and 8 months, and in Arm B were 2.1 months and not reached.

Conclusion: Concurrent ipilimumab 10 $\mathrm{mg} / \mathrm{kg}$ with SRS is safe. The WBRT arm was closed early due to slow accrual, but demonstrated safety with ipilimumab 3 $\mathrm{mg} / \mathrm{kg}$. No patient experienced DLT. Larger studies with ipilimumab $10 \mathrm{mg} / \mathrm{kg}$ and SRS are warranted.

\section{INTRODUCTION}

Brain metastases (BM) occur in more than half of patients with advanced melanoma, and central nervous system disease burden often contributes to their death. 1,2 The historic median survival of patients with BM from melanoma is 4.7 months. ${ }^{3}$ Traditional BM treatment options includes surgery, whole brain radiation therapy (WBRT), and stereotactic radiosurgery (SRS), and can prevent neurological decline and may also improve overall (OS). ${ }^{4-7}$ There has been increasing interest in radiotherapy (RT) combined with immunotherapy (IT) with growing evidence supporting a potential synergistic effect. It remains unclear the role that this synergism has on toxicity. ${ }^{8}$

Activated T-cells and antibodies targeting tumor-associated antigens (TAAs) detected in blood from cancer patients supports an active role for an anti-tumor immune response. ${ }^{9}$ T-cell infiltrates in melanoma have prognostic significance, and when identified within nodal metastases, predict benefit in patients treated with neoadjuvant interferon- $\alpha-2 b .{ }^{10-13}$ Cytotoxic T-lymphocyte-associated antigen 4 (CTLA-4), is a negative regulator of T-cell-mediated anti-tumor immune responses and therefore represents a critical checkpoint, controlling both response duration and intensity. ${ }^{14-16}$ Ipilimumab (MDX-010, Bristol-Myers Squibb) is a fully human monoclonal antibody 


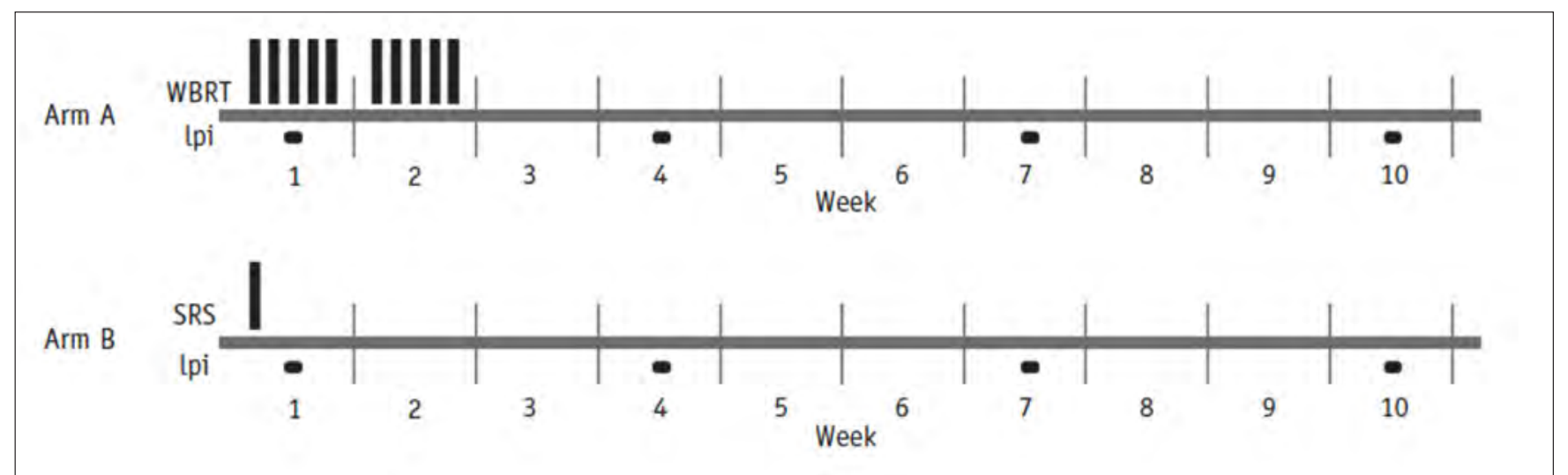

Figure 1. Treatment Schedule

directed against the CTLA-4 receptor and is FDA approved for patients with unresectable or metastatic melanoma. ${ }^{17,18,19}$ One of the larger studies to investigate ipilimumab evaluated 127 patients and demonstrated an OS benefit (93 v. 42 weeks, $\mathrm{P}=0.0028$ ) for patients who received concomitant IT and $R T .20$

Early in vitro studies showing a broad shoulder in the cell survival curves and a high repair rate in melanoma cells have inferred better tumor response with higher radiation doses. ${ }^{21,22}$ Moreover, SRS delivery in close proximity to IT yields the possibility of increased immunomodulation which has been hypothesized to have an effect on distant control. This so-called "abscopal effect" is rare and intriguing, although specific mechanisms are currently incompletely understood. ${ }^{23,24}$ In addition to the potential immunogenic advantages, concomitant treatment also limits delays in subsequent therapy.

To the best of our knowledge, we report the first prospective phase I study evaluating concurrent ipilimumab with SRS or WBRT for patients with melanoma BM, assessing the safety and tolerability of concomitant therapy as well as intracranial (IC) and extracranial (EC) control, progression-free survival (PFS), and OS.

\section{MATERIALS AND METHODS}

Study Design and Participants

This IRB-approved, open-label, phase I, clinical trial was performed between October 2012 and August 2014, at Thomas Jefferson University and Ohio State University. All patients were over 18 years old, Eastern Cooperative Oncology Group (ECOG) performance status 0 or 1 , with normal hepatic and renal function and with histologic and radiographic confirmation of diagnosis. Blood count requirements were as follows: absolute neutrophil count $\geq 1000 / \mu \mathrm{L}$, hemoglobin $\geq 9 \mathrm{~g} / \mathrm{dL}$, platelets $\geq 75,000 / \mu \mathrm{L}$. Patients were excluded if they had a history of chronic infection (HIV or Hepatitis), autoimmune condition, abnormal thyroid function, or leptomeningeal carcinomatosis.

\section{Radiotherapy}

Patients were enrolled onto one of two arms depending on their IC disease burden. Arm A (WBRT) included patients with 5 or more BM, any lesion $>4 \mathrm{~cm}$ maximal diameter, or 1 completely resected BM with postoperative cavity $>4$ $\mathrm{cm}$. Arm B (SRS) included patients with fewer than $5 \mathrm{BM}$ (all $\leq 4 \mathrm{~cm}$ in diameter) or a single postoperative cavity $<4 \mathrm{~cm}$. Within each arm, RT dose was predetermined. WBRT dose was 30 Gy in 10 fractions. Ipilimumab was administered on day 3 of RT in Arm A. Arm B patients received SRS according to the maximum diameter of the BM or resection cavity according to dose prescriptions in RTOG 90-05.25 Ipilimumab was administered 2 days following SRS in Arm B (Figure 1).

\section{Dose-Escalation Scheme}

Ipilimumab was administered intravenously over 90 minutes once every 3 weeks for 4 total doses and was doseescalated independently in each arm with no intra-patient escalation. The FDA approved dose of $3 \mathrm{mg} / \mathrm{kg}$ was the starting dose. Rationale for ipilimumab dose escalation to $10 \mathrm{mg} / \mathrm{kg}$ was based on findings from the randomized, double-blind, phase 2 dose-ranging study of ipilimumab monotherapy demonstrating the best overall response rate in the $10 \mathrm{mg} /$ $\mathrm{kg}$ group $(11.1 \%, 95 \% \mathrm{Cl} 4.9-10.7)$ versus the $3 \mathrm{mg} / \mathrm{kg}$ group $(4.2 \%, 95 \% \mathrm{Cl} 0.9-11.7)$, suggesting further investigation of this higher dose. ${ }^{26}$ Following the initial 4 treatments, maintenance dosing was offered to patients without unacceptable toxicity (refractory grade $>3$ immune-related adverse events [irAEs]) at the same dose level given every 12 weeks until disease progression, toxicity requiring discontinuation, or consent withdrawal.

\section{Dose-Limiting Toxicity}

Adverse events (AEs) were recorded with the Common Terminology Criteria for Adverse Events version 4.0 (CTCAE v.4). Dose-limiting toxicity (DLT) was defined as any grade 3 or higher treatment related toxicity occurring within 30 days of completing RT. Any neurological toxicity of grade 3, 4, or 5 was considered doselimiting (except symptoms present prior to study enrollment or expected sequelae of surgery or SRS). All patients were followed for AEs for 4 weeks following the last dose of ipilimumab. Intratumoral hemorrhage 


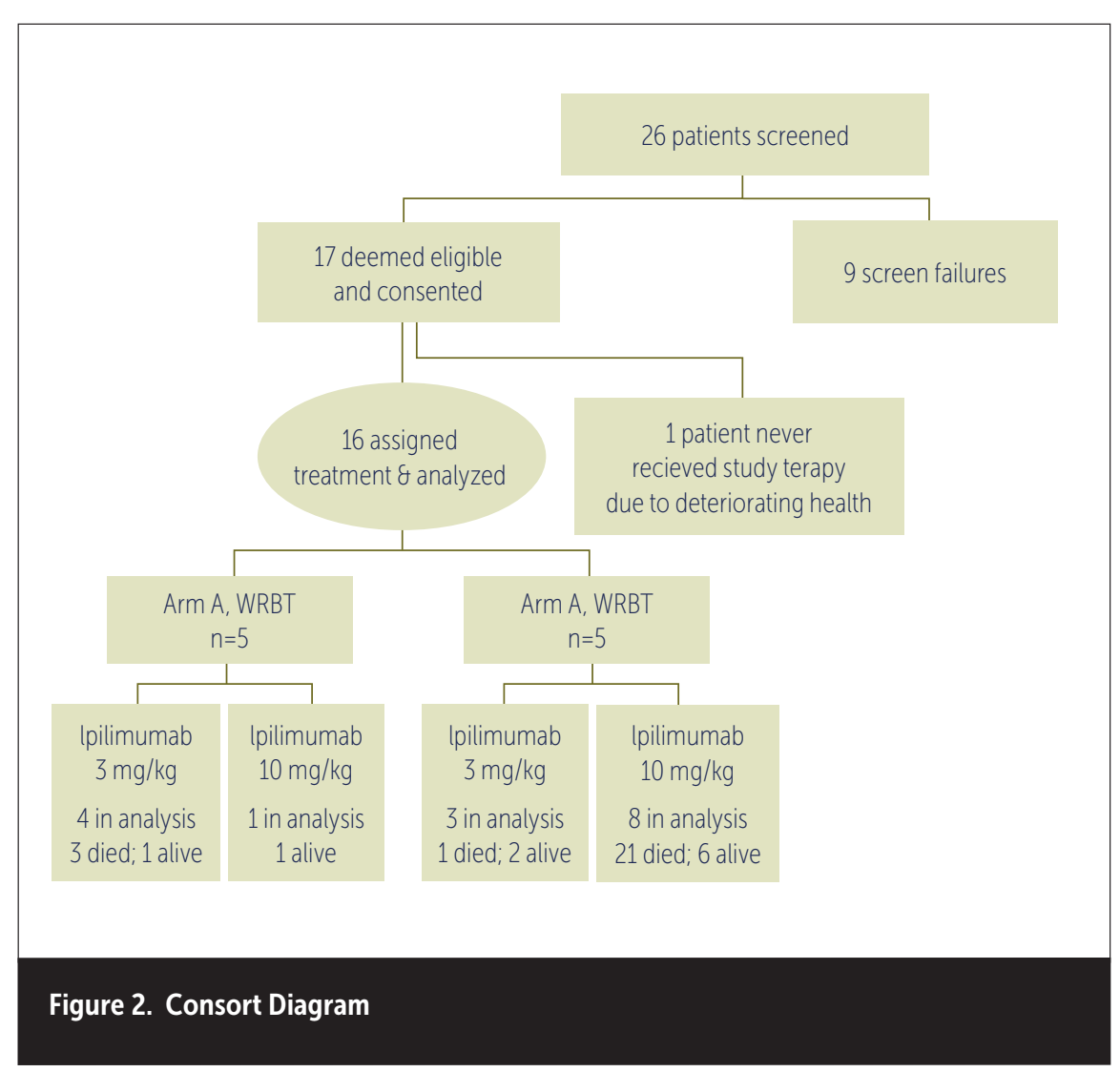

was defined as new or worsening signs of bleeding within the irradiated tumor or cavity volume.

\section{Assessment of Efficacy}

Contrast-enhanced MRI of the brain was performed at week 7 and then every 2 months for 1 year, then every 3 months. All MRIs were interpreted using Response Evaluation Criteria In Solid Tumors (RECIST, version 1.1$)^{27}$ and immunerelated response criteria (irRC). ${ }^{28}$ Overall response using irRC was classified as immune-related complete response (irCR), partial response (irPR), stable disease (irSD), or progressive disease (irPD) based on the predefined combination of parameters. ${ }^{28}$ For evaluation of EC disease, CT of the chest, abdomen, and pelvis was performed at week 7 and 13 following enrollment, and every 3 months subsequently.

\section{Statistical Methodology}

A two-stage $3+3$ accrual design ${ }^{29}$ was used at each dose considered with goal death or last patient contact (censored observation). Analysis of EC control, new BM development, and safety/tolerability was done separately for each arm. All subjects enrolled in the study who received at least one dose of ipilimumab were analyzed

\section{Role of the Funding Source}

This study was funded by Bristol-Myers Squibb (New York City, NY) which provided the study drug and worked with the senior authors in the design and analysis. All authors jointly approved this work for submission and confirm the accuracy of the data. No additional authors not listed contributed to this work. All authors affirm that this trial was performed in accordance with the protocol and all amendments.

\section{RESULTS}

\section{Patient Characteristics}

Of the 26 patients screened for the trial, 17 signed informed consent and were deemed eligible. One patient never received protocol therapy due to deteriorating health following consent. Sixteen patients received study therapy and were analyzed (Figure 2). Table 1 summarizes the patient and clinical characteristics, separately for the two arms. Overall, the mean age at time of BM diagnosis was 60 (SD, $5-13$ ) and $75 \%$ of the patients were male. There were 8 patients each with ECOG performance status of 0 and 1 . Nine patients $(56 \%)$ had initial BM surgery. Thirteen patients (81\%) had EC metastases at the time of BM diagnosis and 5 (38\%) received $\mathrm{RT}$ for their EC disease.

In Arm A (WBRT, $\mathrm{n}=5$ ), the median number of lesions was 6 (range, 1 to $>10$ ) and the dose was 30 Gy in 10 fractions for all patients. In Arm B (SRS, n=11, the median number of lesions was 2 (range, 1 to 3) and the median dose was 24 Gy (range, 15 to $24 \mathrm{~Gy}$ ). In total, 20 lesions/ cavities were treated with SRS with a median planning target volume of 3.25 cc per individual lesion (range, 0.1-22.7 cc). The median per patient treatment volume was $8.5 \mathrm{cc}$ (range 0.5-29.2 cc). The median number of completed cycles of ipilimumab was as follows: 4 (range, 2 - 4+14 maintenance) for dose level $3 \mathrm{mg} / \mathrm{kg}(\mathrm{n}=7)$, and 3 (range, 2 - 4 


\begin{tabular}{|c|c|c|c|}
\hline \multicolumn{3}{|l|}{ Characteristic } & Value \\
\hline \multicolumn{4}{|l|}{ Patients ( $n=16)$} \\
\hline \multicolumn{3}{|l|}{ Mean age at IC diagnosis (range) } & $60(37-75)$ \\
\hline \multirow[t]{2}{*}{ Sex, No. (\%) } & \multicolumn{2}{|c|}{ Male } & $13(81 \%)$ \\
\hline & \multicolumn{2}{|c|}{ Female } & $3(19 \%)$ \\
\hline \multirow[t]{3}{*}{ ECOG performance status (n) } & \multicolumn{2}{|l|}{0} & 8 \\
\hline & \multicolumn{2}{|l|}{1} & 7 \\
\hline & \multicolumn{2}{|l|}{2} & 1 \\
\hline \multicolumn{3}{|c|}{ Number with extracranial metastases } & $13(81 \%)$ \\
\hline \multicolumn{3}{|l|}{ Number with pre-RT surgery } & $8(50 \%)$ \\
\hline \multirow[t]{5}{*}{ Radiation technique } & \multicolumn{2}{|l|}{ WBRT } & $5(31 \%)$ \\
\hline & \multicolumn{2}{|c|}{ Median \# lesions (range) } & $6(1->10)$ \\
\hline & \multicolumn{2}{|l|}{ SRS } & $11(19 \%)$ \\
\hline & \multicolumn{2}{|c|}{ Median \# lesions (range) } & $2(1-3)$ \\
\hline & \multicolumn{2}{|c|}{ Median dose, Gy (range) } & $24(15-24)$ \\
\hline \multirow[t]{4}{*}{ Ipilimumab } & Dose & $3 \mathrm{mg} / \mathrm{kg}$ & 9 \\
\hline & \multicolumn{2}{|c|}{ Median \# cycles completed (range) } & $\begin{array}{l}4(2-4+14 \text { mainte- } \\
\text { nance) }\end{array}$ \\
\hline & Dose & $10 \mathrm{mg} / \mathrm{kg}$ & 7 \\
\hline & \multicolumn{2}{|c|}{ Median \# cycles completed (range) } & $3(2-4)$ \\
\hline \multicolumn{3}{|c|}{ Median length of follow-up after RT, months (range) } & $9.1(2-37)$ \\
\hline
\end{tabular}

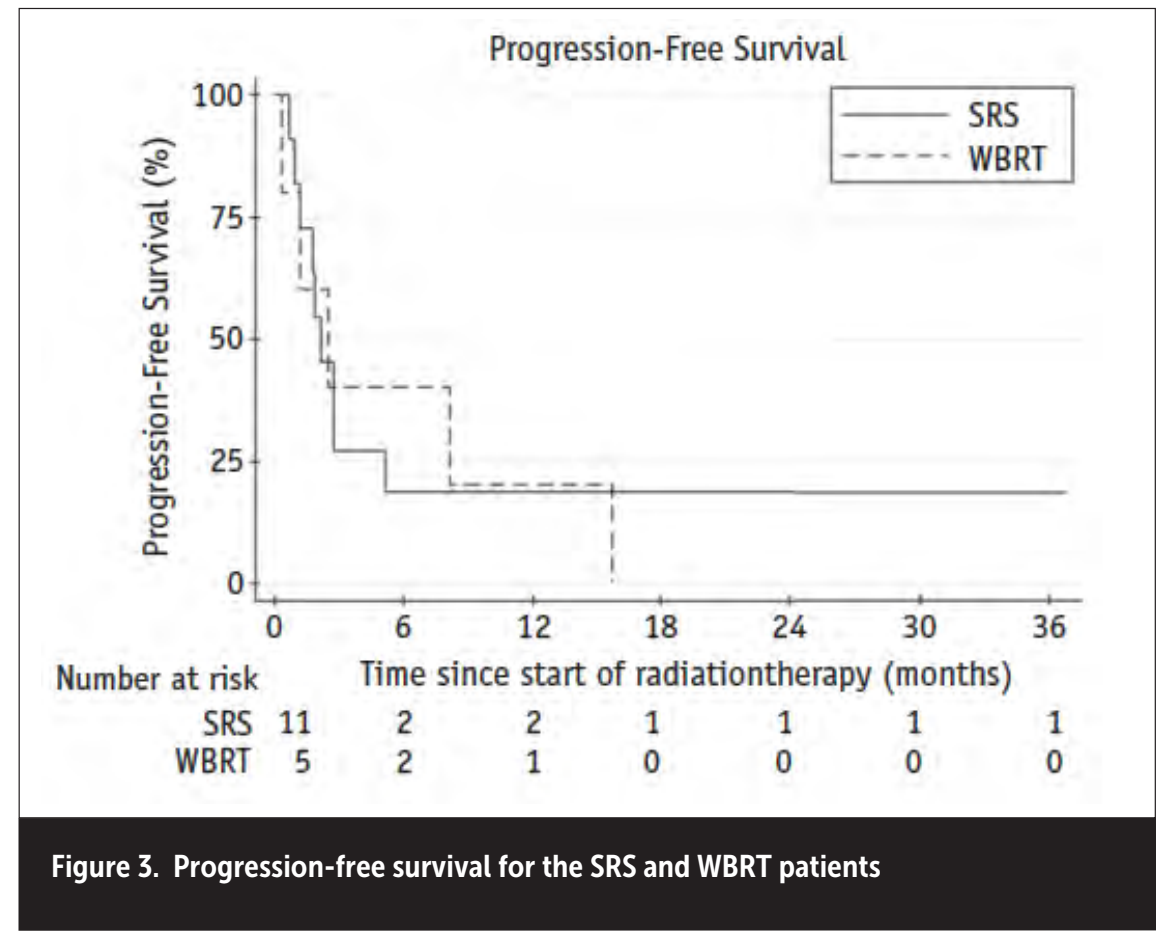

maintenance) for dose level $10 \mathrm{mg} / \mathrm{kg}$ $(n=9)$. Two patients in both arms received pre-treatment dexamethasone (mean dose $6 \mathrm{mg} /$ day and $3.5 \mathrm{mg} /$ day in the SRS and WBRT arms, respectively).

\section{Toxicity}

Ipilimumab in combination with RT was well tolerated. There were 21 grade 1-2 neurotoxic effects including the following: headache $(n=6,37.5 \%)$, nausea/vomiting ( $n=3,18.8 \%)$, subclinical intracranial hemorrhage $(n=4,25 \%)$, dizziness $(n=1,6.3 \%)$, vision changes $(n=1,6.3 \%)$, tinnitus/hearing loss $(n=3$, $18.8 \%)$, facial palsy $(n=1,6.3 \%)$, weakness/neuropathy $(n=1,6.3 \%)$, and seizure $(n=1,6.3 \%)$. There were no documented reports of pseudoprogression in our small sample of patients.

One patient experienced headache prompting emergency room evaluation, categorized as a grade 3 neurotoxic event. This toxicity occurred following SRS but prior to first IT administration and was therefore not considered a dose-limiting toxicity (DLT), but rather, an effect of surgery and SRS. The patient went on to receive 4 doses of ipilimumab plus one maintenance cycle prior to disease progression. There were no additional grade 3 neurotoxicities

Table 2 summarizes the AEs in detail. In addition to the neurotoxicity above, there were 10 additional grade 3 toxicities, including gastrointestinal most commonly $(n=5,31 \%)$. There were no grade 4 or 5 toxicities. Of note, no patients experienced radionecrosis

\section{Progression-Free Survival and Overall Survival}

Median follow-up time was 8.0 months in Arm A (range, 3.5 to 24.1) and 10.5 months in Arm B (range, 1.8 to 36.8) from first day of RT to last follow-up or death. At time of analysis, no patients were still on treatment. Fourteen patients in total progressed and/or died during the study's follow-up (5/5 = 100\% in Arm A and $9 / 11=82 \%$ in Arm B). Thirteen patients had IC progression (including the 6 who subsequently died). Median time to IC progression was 2.53 months (WBRT, range $0.3-18$ ) versus 2.45 months (SRS, range 1-37). Overall response intracranially as defined by the irRC (15 


\begin{tabular}{|c|c|c|c|c|c|c|}
\hline & \multicolumn{2}{|c|}{ Grade 1 - 2} & \multicolumn{2}{|c|}{ Grade 3} & \multicolumn{2}{|c|}{ Grade 4} \\
\hline & SRS & WBRT & SRS & WBRT & SRS & WBRT \\
\hline Headache & 4 & 2 & 1 & 0 & 0 & 0 \\
\hline $\begin{array}{l}\text { Post-treatment subclinical intracranial } \\
\text { hemorrhage }\end{array}$ & 4 & 0 & 0 & 0 & 0 & 0 \\
\hline Nausea, vomiting, abdominal pain & 2 & 1 & 0 & 0 & 0 & 0 \\
\hline Fatigue & 1 & 1 & 0 & 1 & 0 & 0 \\
\hline Hearing loss, otitis, tinnitus & 1 & 2 & 0 & 0 & 0 & 0 \\
\hline Skin reaction, pruritis & 2 & 3 & 0 & 0 & 0 & 0 \\
\hline Diarrhea & 3 & 2 & 4 & 1 & 0 & 0 \\
\hline Insomnia & 0 & 1 & 0 & 0 & 0 & 0 \\
\hline Anorexia & 1 & 2 & 0 & 0 & 0 & 0 \\
\hline Hot flashes & 0 & 1 & 0 & 0 & 0 & 0 \\
\hline Constipation & 0 & 1 & 0 & 0 & 0 & 0 \\
\hline Lymphopenia & 1 & 0 & 0 & 1 & 0 & 0 \\
\hline Visual changes & 0 & 1 & 0 & 0 & 0 & 0 \\
\hline Hypophysitis & 0 & 0 & 0 & 1 & 0 & 0 \\
\hline Hypertension & 0 & 1 & 0 & 0 & 0 & 0 \\
\hline Alopecia & 0 & 2 & 0 & 0 & 0 & 0 \\
\hline Dizziness & 0 & 1 & 0 & 0 & 0 & 0 \\
\hline Bone pain & 0 & 1 & 0 & 0 & 0 & 0 \\
\hline Anemia & 1 & 1 & 1 & 0 & 0 & 0 \\
\hline Thrombocyopenia & 1 & 0 & 0 & 0 & 0 & 0 \\
\hline Depression & 1 & 0 & 0 & 0 & 0 & 0 \\
\hline Lipase increase & 1 & 0 & 0 & 0 & 0 & 0 \\
\hline Weakness, neuropathy & 1 & 0 & 0 & 0 & 0 & 0 \\
\hline Seizure & 1 & 0 & 0 & 0 & 0 & 0 \\
\hline Facial palsy & 1 & 0 & 0 & 0 & 0 & 0 \\
\hline Pleuritic pain, effusion & 1 & 0 & 0 & 0 & 0 & 0 \\
\hline
\end{tabular}

with treatment sites as follows: lung $(n=2)$, thoracic/lumbar vertebrae and lower leg soft tissue metastasis $(n=1)$. Of the 3 patients with no EC disease at the time of BM diagnosis, all 3 remained without EC disease at 2 month follow-up. Overall, 6 patients experienced EC progression at 2 months, 5 patients had stable disease, 3 patients continued with no EC disease, 1 patient had a partial response (after having her EC disease treated), and 1 patient did not receive systemic imaging at the 2 month time point.

Seven patients developed new BM (as differentiated from previously treated $B M$ ) on follow-up imaging (Arm A, n=1 and Arm $B, n=6)$ with the median time from first RT fraction to new BM diagnosis of 1.9 months (range, 0.97 to 8.2). The median time from first RT fraction to development of new BM in the one patient having received WBRT was 8.2 months.

\section{DISCUSSION}

To the best of our knowledge, we report the first prospective phase I study evaluating concurrent ipilimumab with SRS or WBRT for patients with melanoma BM. The toxicity profile of escalating doses of ipilimumab demonstrated no grade $4 / 5$ toxicity, radionecrosis, or DLTs. Ipilimumab $10 \mathrm{mg} / \mathrm{kg}$ with SRS is safe and we recommend this dose for further study with concurrent SRS. Additional phase I studies will be necessary to determine the safety of WBRT with ipilimumab 10 $\mathrm{mg} / \mathrm{kg}$, as we had to terminate this part of the trial due to slow accrual, however safety was demonstrated with concurrent WBRT and ipilimumab $3 \mathrm{mg} / \mathrm{kg}$.

CA184-04230 was a phase II trial that evaluated ipilimumab in patients with melanoma BM. Patients were specifically excluded from the trial if they received any RT within 14 days of ipilimumab and only $8 \%$ of patients had received prior SRS. There were no unexpected toxicities and activity was demonstrated particularly when BM were small and asymptomatic. ${ }^{30}$ However, this trial does not specifically evaluate the safety of concurrent RT and ipilimumab.

Hodi et al ${ }^{18}$ reported a large study evaluating 676 patients randomized to receive ipilimumab $3 \mathrm{mg} / \mathrm{kg}$ in combination with an investigational peptide vaccine 


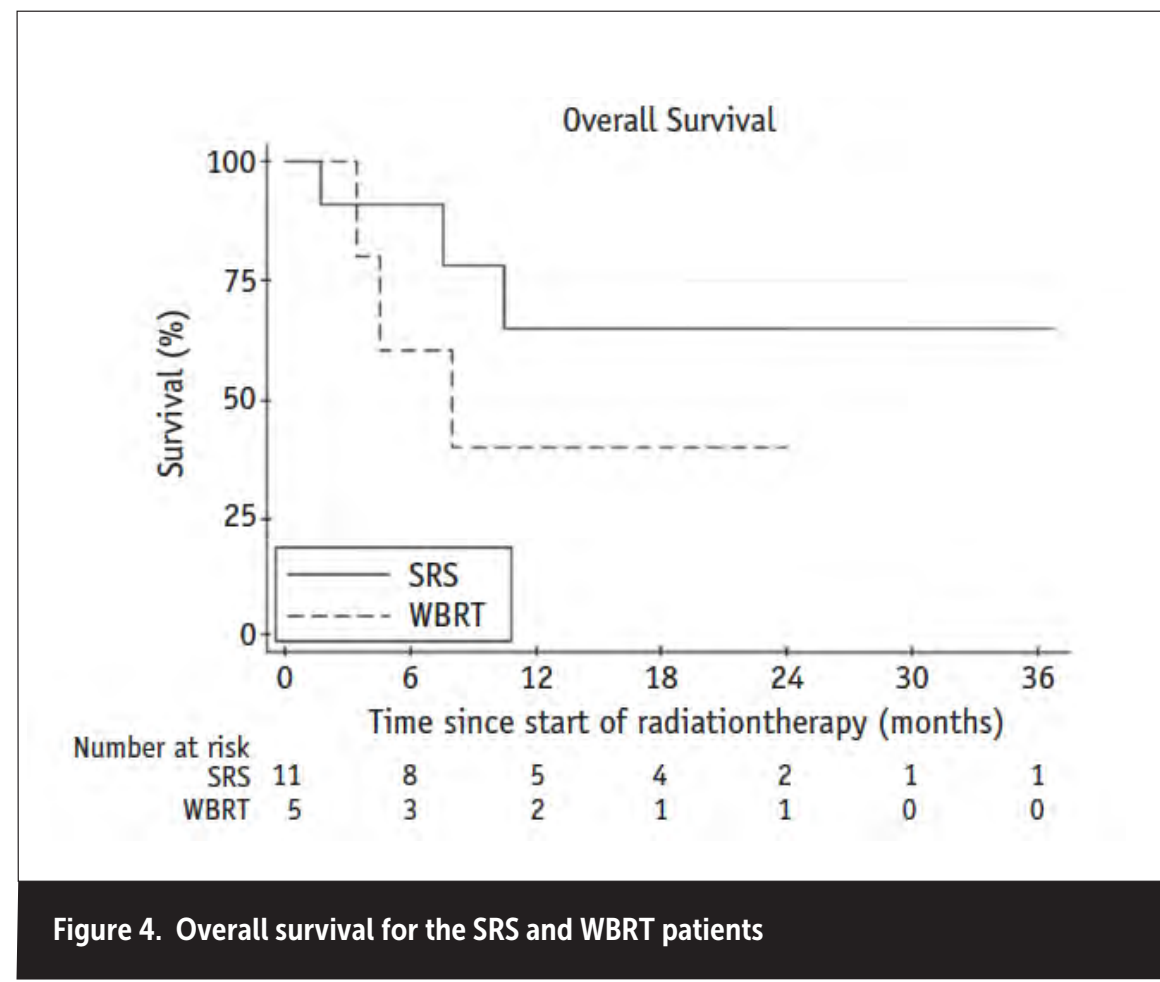

(gp100), ipilimumab alone, or gp100 alone. OS was 10.0 months in patients receiving ipilimumab plus gp100, compared to 10.1 months in the ipilimumab alone arm and 6.4 months in the gp100 alone arm ( $p<0.001)$. Eighty-two patients $(12.1 \%)$ had CNS disease in this study. ${ }^{18}$ This data is comparable to our study with the median OS not reached in the SRS arm and 8 months in the WBRT arm (median follow-up 10.5 and 8 months, respectively). Given that OS has not been reached in the SRS arm of our trial, we hypothesize that the timing of ipilimumab in close proximity to SRS may mechanistically promote duration and intensity of response in these patients, although this study is hypothesis-generating in that regard.

To this end, a recent report by Johnson et al. ${ }^{31}$ demonstrated the impact of systemic agents on the clinical outcomes of patients with BM. Although this review included patients with many primary tumor types, and a variety of agents (BRAF inhibitors, ipilimumab in patients with melanoma primaries), the authors did show that patients receiving IT with SRS compared to SRS alone had a median survival of 18 versus 7 months and a 1 -year OS of $65 \%$ versus $30 \%$ $(p<0.0001) .{ }^{31}$

In terms post-RT lesion size, reports with Qian et al. ${ }^{8}$ recently reported results regarding 313 melanoma BMs in 53 patients treated concurrently (defined as RT and IT delivery within 4 weeks of each other). 8 IT was as follows: 54 patients $(72 \%)$ received anti-CTLA-4 and 21 patients $(28 \%)$ received antiPD-1. No patients received combination IT. The median percent reduction in lesion volume was significantly greater for the concurrent group. The timing of IT and SRS did not appear to effect post-treatment lesion size. ${ }^{8}$ In this report, only 39 lesions in 24 patients demonstrated regrowth to $>120 \%$ baseline volume. Authors concluded that the early response is greater and more rapid with concurrent therapy. There was not specific mention of tumor hemorrhage in this study. ${ }^{8}$ In contrast to this report, preliminary data reported by Shen et al. showed an increase in lesion size in 13 of 26 lesions treated concurrently (defined as IT starting "prior to or with SRS"). 32 Lesion enlargement in the SRS alone cohort occurred with similar frequency. combined therapy have been conflicting.
Seven of the 13 patients treated concurrently had documented hemorrhage partially accounting for the enlargement and 2 lesions had documented recurrence. Of note, the IT was not standardized in this retrospective review and included ipilimumab, nivolumab, and pembrolizumab. 32

Kiess et al. ${ }^{33}$ retrospectively reported response and toxicity on 46 patients with melanoma BM who received ipilimumab (3 $\mathrm{mg} / \mathrm{kg}$ or $10 \mathrm{mg} / \mathrm{kg}$ ) with SRS (median dose 21 Gy) between 2005 and 2011. Patients treated with SRS either before or during ipilimumab had improved OS compared to those having SRS afterward (1-year OS $56 \%$ vs $65 \%$ vs $40 \%, p=0.008$ ). Moreover, only approximately $20 \%$ of patients experienced grade 3 or 4 toxicities. Interestingly, SRS before or during IT was more likely to be associated with a temporary increase in size or hemorrhage of the irradiated lesion, likely secondary to inflammation, and asymptomatic in the majority of cases. ${ }^{33}$ Most likely due to the small numbers in our study and the frequency of neurosurgical intervention prior to SRS (6/11 patients, 55\%), we did not observe the same temporary lesional edema following combination therapy. Similarly, no lesions were deemed to undergo pseudoprogression following SRS.

When evaluating the effects of IT, EC disease control is also of interest. First described in the 1950s, the abscopal effect refers to the seldom-reported phenomenon of tumor regression of a secondary site following RT to a separate primary site. ${ }^{34}$ Seromic analysis and immunologic correlates of the abscopal effect in a patient with melanoma has demonstrated antigenic targets with increased antibody responses following $\mathrm{RT}^{35}$ The surprising response achieved by the patient in this report provided new insight in the mechanisms of combination therapy. Our study evaluated EC control as a secondary endpoint with a similar hypothesis that IT delivered in close proximity to SRS may impact distant control. In our study, we did not observe the abscopal effect extracranially or intracranially at non-target sites.

Limitations of our study include slow accrual to Arm A, leading to its early closure. This arm did show safety with ipilimumab 3 $\mathrm{mg} / \mathrm{kg}$, however. An additional caveat to 


\begin{tabular}{|c|c|c|c|c|c|c|c|c|c|}
\hline $\begin{array}{l}\text { Primary } \\
\text { author }\end{array}$ & Year & Analysis type & Primary & $\begin{array}{l}\text { Patients } \\
\text { who got } \\
\text { SRS (n) }\end{array}$ & IT agent/timing & $\begin{array}{l}\text { Patients } \\
\text { receiving IT } \\
\text { and SRS (\%) }\end{array}$ & $\begin{array}{l}\text { Median } \\
\text { survival } \\
\text { (months) }\end{array}$ & OS & Other \\
\hline Knisely ${ }^{41}$ & 2012 & $\begin{array}{l}\text { Prospectively } \\
\text { collected, } \\
\text { retrospectively }\end{array}$ & melanoma & 7 & $\begin{array}{l}\text { Ipilimumab (SRS first, } \\
n=16 ; \text { IT first, } n=11 \text { ) }\end{array}$ & $27(35 \%)$ & $\begin{array}{l}21.3 \text { (with IT) } \\
\text { v. } 4.9 \text { (no IT) }\end{array}$ & $\begin{array}{l}2 \text { year: } 47.2 \% \\
\text { (with IT) v. } \\
19.7 \% \text { (no IT) } \\
p=0.044\end{array}$ & $\begin{array}{l}\text { Grade } \geq 3 \\
\text { toxicity NR }\end{array}$ \\
\hline Johnson ${ }^{3}$ & 2015 & retrospective & $\begin{array}{l}\text { renal cell, } \\
\text { melanoma, } \\
\text { breast, colon, } \\
\text { esophagus, } \\
\text { lung }\end{array}$ & 737 & $\begin{array}{l}\text { various agents } \\
\text { (including BRAF } \\
\text { inhibitors \& } \\
\text { ipilimumab), IT } \\
\text { concurrently or within } \\
30 \text { days of SRS }\end{array}$ & $167(23 \%)$ & $\begin{array}{l}18 \text { (with IT) } \\
\text { v. } 7 \text { (no IT) }\end{array}$ & $\begin{array}{l}1 \text { year: } 65 \% \\
\text { (with IT) v. } \\
30 \% \text { (no IT) } \\
p<0.0001\end{array}$ & $\begin{array}{l}\text { Grade } \geq 3 \\
\text { toxicity NR }\end{array}$ \\
\hline Kiess $^{3}$ & 2015 & retrospective & melanoma & 46 & $\begin{array}{l}\text { Ipilimumab (concur- } \\
\text { rent, } n=15 \text {; SRS first, } \\
n=19 ; \text { IT first, } n=12 \text { ) }\end{array}$ & $46(100 \%)$ & $\begin{array}{l}12.4 \\
\text { (all patients) }\end{array}$ & $\begin{array}{l}1 \text { year: } 65 \% \\
\text { (concurrent) } \\
\text { v. } 56 \% \text { (SRS } \\
\text { before) v. } 40 \% \\
\text { (IT before) } \\
\text { P=0.008 }\end{array}$ & $\begin{array}{l}1 \text { year } \\
\text { RR: } 69 \% \\
\text { (concurrent) } \\
\text { v. } 64 \% \text { (SRS } \\
\text { before) v. } \\
92 \% \text { (IT } \\
\text { before) } \\
\text { P=0.003 }\end{array}$ \\
\hline Patel ${ }^{42}$ & 2015 & retrospective & melanoma & 54 & $\begin{array}{l}\text { Ipilimumab (within } 4 \\
\text { months of SRS) }\end{array}$ & $20(37 \%)$ & $\begin{array}{l}9.1 \text { (with IT) v. } \\
8.0(\text { no IT) } \\
p=0.84\end{array}$ & NA & $\begin{array}{l}1 \text { year LC: } \\
71.4 \% \text { (with } \\
\text { IT) v. } 92.3 \% \\
\text { (no IT) } \\
p=0.40\end{array}$ \\
\hline
\end{tabular}

NR: not reported; IT: immunotherapy; RR: regional recurrence

our study is that ipilimumab alone is no longer the standard of care for previously untreated advanced melanoma. First-line therapy is now either anti-programmed death 1 (PD-1) inhibitor monotherapy (pembrolizumab or nivolumab) or a combination of nivolumab with ipilimumab. ${ }^{36}$ This combination of therapies improved overall response rate and PFS as compared with either treatment alone, however, demonstrated significantly increased toxicity. Compared to single agent therapy, the effect of combination therapy on OS has not yet been demonstrated. ${ }^{37,38}$ Pembrolizumab alone demonstrated prolonged PFS and OS and had less high-grade toxicity as compared to ipilimumab in patients with advanced melanoma as demonstrated in the KEYNOTE-006 trial. ${ }^{39}$ Based on these results, future studies will need to address RT with combination checkpoint inhibitor therapy or pembrolizumab alone.

An additional limitation is the relatively short follow-up possibly limiting the capture of late toxicity. The median follow-up in the arm receiving SRS was 10.5 months which may be long enough to catch some, but not all cases of radionecrosis. A recent report by Colaco et al. ${ }^{40}$ evaluating 180 patients with BM who received radiosurgery with either cytotoxic chemotherapy, targeted therapy, or IT noted a significantly increased rate of radionecrosis or treatment-related imaging changes in the IT group (OR 2.40 [95\% Cl 1.06-5.44]; $p=0.03$ ). ${ }^{40}$ The median follow-up was 11.7 months and $31 \%$ of patients had melanoma primaries. Of importance, $30 \%$ of patients received prior WBRT which increases one's risk for subsequent radionecrosis following radiosurgery. For patients who received IT alone, median time to radionecrosis development was 10.2 months (range, 2.8-22.1 months), which is slightly shorter than the median follow-up in our SRS arm. ${ }^{40}$ Therefore, although our study does have relatively short follow-up, it is worthwhile to demonstrate that we have no documented cases of radionecrosis.

In an era where combined modality targeted therapy is becoming more promising and increasingly utilized, it is important to establish the safety profiles of these modalities. ${ }^{41}$ Our results demonstrate the safety of combining SRS with either ipilimumab 3 mg/kg or $10 \mathrm{mg} / \mathrm{kg}$.

Future exploration of multi-agent immunotherapy in combination with SRS for melanoma BM is warranted, although currently there are no clinical trials open to accrual evaluating the safety and efficacy of this combination of treatment. 


\section{REFERENCES}

1. Bafaloukos D, Gogas H. The treatment of brain metastases in melanoma patients. Cancer Treat Rev. 2004;30(6):515-520. doi:10.1016/j.ctrv.2004.05.001.

2. Sampson JH, Carter JH, Friedman AH, Seigler HF. Demographics, prognosis, and therapy in 702 patients with brain metastases from malignant melanoma. J Neurosurg. 1998;88(1):1120. doi:10.3171/jns.1998.88.1.0011.

3. Davies MA, Liu P, Mclntyre S, Kim KB, Papadopoulos N, Hwu WJ, Hwu P, Bedikian A. Prognostic factors for survival in melanoma patients with brain metastases.

Cancer. 2011 Apr 15;117(8):1687-96. doi: 10.1002/cncr.25634. PubMed PMID: 20960525.

4. Patchell RA, Tibbs PA, Regine WF, et al. Postoperative radiotherapy in the treatment of single metastases to the brain: a randomized trial. JAMA. 1998;4(280(17)):1485-1489. doi:joc80445 [pii].

5. Patchell RA, Tibbs PA, Walsh JW, et al. A Randomized Trial of Surgery in the Treatment of Single Metastases to the Brain. Vol 322. 1990. doi:10.1056/NEJM199002223220802.

6. Andrews DW. Current Neurosurgical Management of Brain Metastases. Semin Oncol. 2008;35(2):100-107. doi:10.1053/j. seminoncol.2007.12.003.

7. Thomas SS, Dunbar EM. Modern multidisciplinary management of brain metastases. Curr Oncol Rep. 2010;12(1):34-40. doi:10.1007/ s11912-009-0073-8.

8. Qian JM, Yu JB, Kluger HM, Chiang VL. Timing and type of immune checkpoint therapy affect the early radiographic response of melanoma brain metastases to stereotactic radiosurgery. Cancer. 2016 Jun 10. doi: 10.1002/cncr.30138. [Epub ahead of print] PubMed PMID: 27285122.

9. Nagorsen D, Scheibenbogen C, Marincola FM, et al. Natural T cell immunity against cancer. Clin Cancer Res 2003;9:4296-4303.

10. Clemente CG, Minm MC, Jr., Bufalino R, et al. Prognostic value of tumor infiltrating lymphocytes in the vertical growth phase of primary cutaneous melanoma. Cancer 1996;77:1303-1310.

11. Hakansson A, Gustafsson B, Krysander L, et al. Tumour-infiltrating lymphocytes in metastatic malignant melanoma and response to interferon alpha treatment. $\mathrm{Br} J$ Cancer 1996;74:670-676

12. Mihm MC, Jr., Clemente CG, Cascinelli N Tumor infiltrating lymphocytes in lymph node melanoma metastases: a histopathologic prognostic indicator and an expression of local immune response. Lab Invest 1996;74:43-47.
13. Moschos SJ, Edington HD, Land SR, et al. Neoadjuvant treatment of regional stage IIIB melanoma with high-dose interferon alfa- $2 b$ induces objective tumor regression in association with modulation of tumor infiltrating host cellular immune responses. J Clin Oncol 2006:24:3164-3171.

14. Peggs KS, Quezada SA, Korman AJ, et al. Principles and use of anti-CTLA4 antibody in human cancer immunotherapy. Curr Opin Immunol 2006;18:206-213.

15. Robert C, Ghiringhelli F. What is the role of cytotoxic $T$ lymphocyte-associated antigen 4 blockade in patients with metastatic melanoma? Oncologist 2009;14:848-861.

16. Kaehler KC, Piel S, Livingstone E, et al. Update on immunologic therapy with anti-CTLA-4 antibodies in melanoma: identification of clinical and biological response patterns, immune-related adverse events, and their management. Semin Oncol 2010;37:485-498.

17. Morse MA. Technology evaluation: ipilimumab, Medarex/Bristol-Myers Squibb. Curr Opin Mol Ther 2005;7:588-597.

18. Hodi FS, O'Day SJ, McDermott DF, et al. Improved survival with ipilimumab in patients with metastatic melanoma. $N$ Engl J Med 2010;363:711-723.

19. Weber JS, O'Day S, Urba W, et al. Phase I/II study of ipilimumab for patients with metastatic melanoma. J Clin Oncol 2008;26:59505956.

20. Theurich S, Rothschild SI, Hoffmann M, Fabri M, Sommer A, Garcia-Marquez M, Thelen M, Schill C, Merki R, Schmid T, Koeberle D, Zippelius A, Baues C, Mauch C, Tigges C, Kreuter A, Borggrefe J, von Bergwelt-Baildon M, Schlaak M. Local Tumor Treatment in Combination with Systemic Ipilimumab Immunotherapy Prolongs Overall Survival in Patients with Advanced Malignant Melanoma. Cancer Immunol Res. 2016 Sep 2;4(9):74454. doi: 10.1158/2326-6066.CIR-15-0156. PubMed PMID: 27466265

21. Dewey DL. The radiosensitivity of melanoma cells in culture. Br J Radiol. 1971 Oct;44(526) 816-7. PubMed PMID: 5165659.

22. Barranco SC, Romsdahl MM, Humphrey RM. The radiation response of human malignant melanoma cells grown in vitro. Cancer Res. 1971 Jun;31(6):830-3. PubMed PMID: 5088486.

23. Bernier J. Immuno-oncology: Allying forces of radio- and immuno-therapy to enhance cancer cell killing. Crit Rev Oncol Hematol. 2016 Dec;108:97-108. doi: 10.1016/j.critrevonc.2016.11.001. Review. PubMed PMID: 27931845.

24. Popp I, Grosu AL, Niedermann G, Duda DG. Immune modulation by hypofractionated stereotactic radiation therapy: Therapeutic implications. Radiother Oncol. 2016 Aug;120(2):185-94. doi: 10.1016/j. radonc.2016.07.013. Review. PubMed PMID: 27495145
25. Shaw $E$, Scott $C$, Souhami $L$, et al. Single dose radiosurgical treatment of recurrent previously irradiated primary brain tumors and brain metastases: final report of RTOG protocol 90-05. Int J Radiat Oncol Biol Phys 2000;47:291-298.

26. Wolchok JD, Neyns B, Linette, G, et al. Ipilimumab monotherapy in patients with pretreated advanced melanoma: A randomised, double-blind, multicentre, phase 2, dose-ranging study Lancet Oncol, 11 (2010), pp. 155-164

27. Eisenhauer EA, Therasse P, Bogaerts J, Schwartz LH, Sargent D, Ford R, Dancey J, Arbuck S, Gwyther S, Mooney M, Rubinstein L, Shankar L, Dodd L, Kaplan R, Lacombe D. Verweij J. New response evaluation criteria in solid tumours: revised RECIST guideline (version 1.1). Eur J Cancer. 2009 Jan;45(2):228-47. doi:10.1016/j. ejca.2008.10.026. PubMed PMID: 19097774

28. Wolchok JD, Hoos A, O'Day S, Weber JS, Hamid O, Lebbé C, Maio M, Binder M, Bohnsack O, Nichol G, Humphrey R, Hodi FS. Guidelines for the evaluation of immune therapy activity in solid tumors: immune-related response criteria. Clin Cancer Res. 2009 Dec 1;15(23):7412-20. doi: 10.1158/1078-0432.CCR-09-1624. Epub 2009 Nov 24. PubMed PMID: 19934295

29. Storer BE. Design and analysis of phase I clinical trials. Biometrics. 1989 Sep;45(3):92537. PubMed PMID: 2790129.

30. Margolin K, Ernstoff MS, Hamid O, Lawrence D, McDermott D, Puzanov I, Wolchok JD, Clark JI, Sznol M, Logan TF, Richards J, Michener T, Balogh A, Heller KN, Hodi FS. Ipilimumab in patients with melanoma and brain metastases: an open-label, phase 2 trial. Lancet Oncol. 2012 May;13(5):459-65. doi: 10.1016/S1470-2045(12)70090-6. Epub 2012 Mar 27. PubMed PMID: 22456429.

31. Johnson AG, Ruiz J, Hughes R, Page BR, Isom S, Lucas JT, McTyre ER, Houseknecht KW, Ayala-Peacock DN, Bourland DJ, Hinson WH, Laxton AW, Tatter SB, Debinski W, Watabe K, Chan MD. Impact of systemic targeted agents on the clinical outcomes of patients with brain metastases. Oncotarget. 2015 Aug 7:6(22):18945-55. PubMed PMID: 26087184; PubMed Central PMCID: PMC4662466.

32. Shen C, Lin DD, Redmond KJ, Link K, Kummerlowe M, Douglass J, Lipson EJ, Sharfman W, Bettegowda C, Lim M, Kleinberg LR. Imaging and Clinical Profile Following Concurrent Stereotactic Radiation and Immune Therapy for Melanoma Brain Metastases: Preliminary Results. Int J Radiat Oncol Biol Phys. 2016 Oct 1;96(2S):E134. doi: 10.1016/j.jirobp.2016.06.927. PubMed PMID: 27673866 
33. Kiess AP, Wolchok JD, Barker CA, Postow MA, Tabar V, Huse JT, Chan TA, Yamada Y, Beal K. Stereotactic radiosurgery for melanoma brain metastases in patients receiving ipilimumab: safety profile and efficacy of combined treatment. Int J Radiat Oncol Biol Phys. 2015 Jun 1;92(2):368-75. doi:10.1016/j. ijrobp.2015.01.004. Epub 2015 Mar 5. PubMed PMID: 25754629; PubMed Central PMCID: PMC4955924

34. Mole $\mathrm{RH}$. Whole body irradiation; radiobiology or medicine? Br J Radiol. 1953 May; 26(305):234-41. PubMed PMID. 13042090.

35. Postow MA, Callahan MK, Barker CA, Yamada Y, Yuan J, Kitano S, Mu Z, Rasalan T, Adamow M, Ritter E, Sedrak C, Jungbluth AA, Chua R, Yang AS, Roman RA, Rosner S, Benson B, Allison JP, Lesokhin AM, Gnjatic S, Wolchok JD. Immunologic correlates of the abscopal effect in a patient with melanoma. N Engl J Med. 2012 Mar 8;366(10):925-31. doi: 10.1056/NEJMoa1112824. PubMed PMID: 22397654: PubMed Central PMCID: PMC3345206.

36. National Comprehensive Cancer Network. Melanoma (Version 1.2017). https://www. nccn.org/professionals/physician_gls/PDF/ melanoma.pdf. Accessed February 7, 2017.
37. Larkin J, Chiarion-Sileni V, Gonzalez R, Grob JJ, Cowey CL, Lao CD, Schadendorf D, Dummer R, Smylie M, Rutkowski P, Ferrucci PF, Hill A, Wagstaff J, Carlino MS, Haanen JB, Maio M, Marquez-Rodas I, McArthur GA, Ascierto PA, Long GV, Callahan MK, Postow MA, Grossmann K, Sznol M Dreno B, Bastholt L, Yang A, Rollin LM, Horak C, Hodi FS, Wolchok JD. Combined Nivolumab and Ipilimumab or Monotherapy in Untreated Melanoma. N Engl J Med. 2015 Jul 2:373(1):23-34 doi: 10.1056/ NEJMoa1504030. PubMed PMID: 26027431.

38. Postow MA, Chesney J, Pavlick AC, Robert C, Grossmann K, McDermott D, Linette GP, Meyer N, Giguere JK, Agarwala SS, Shaheen M, Ernstoff MS, Minor D, Salama AK, Taylor M, Ott PA, Rollin LM, Horak C, Gagnier P, Wolchok JD, Hodi FS. Nivolumab and ipilimumab versus ipilimumab in untreated melanoma. N Engl J Med. 2015 May 21;372(21):2006-17. doi: 10.1056/ NEJMoa1414428. PubMed PMID: 25891304

39. Robert C, Schachter J, Long GV, Arance A, Grob JJ, Mortier L, Daud A, Carlino MS, McNeil C, Lotem M, Larkin J, Lorigan P, Neyns B, Blank CU, Hamid O, Mateus C, ShapiraFrommer R, Kosh M, Zhou H, Ibrahim N, Ebbinghaus S, Ribas A; KEYNOTE-006 investigators.. Pembrolizumab versus Ipilimumab in Advanced Melanoma. N Engl J Med. 2015 Jun 25;372(26):2521-32. doi: 10.1056/ NEJMoa1503093. PubMed PMID: 25891173.
40. Colaco RJ, Martin P, Kluger HM, Yu JB, Chiang VL. Does immunotherapy increase the rate of radiation necrosis after radiosurgical treatment of brain metastases? J Neurosurg. 2016 Jul;125(1):17-23. doi: 10.3171/2015.6.JNS142763. PubMed PMID 26544782

41. Vatner RE, Cooper BT, Vanpouille-Box C, Demaria S, Formenti SC. Combinations of immunotherapy and radiation in cancer therapy. Front Oncol. 2014 Nov 28;4:325. doi 10.3389/fonc.2014.00325. eCollection 2014 Review. PubMed PMID: 25506582; PubMed Central PMCID: PMC4246656.

42. Knisely JP, Yu JB, Flanigan J, Sznol M, Kluger HM, Chiang VL. Radiosurgery for melanoma brain metastases in the ipilimumab era and the possibility of longer survival. J Neurosurg. 2012 Aug;117(2):227-33. doi: 10.3171/2012.5.JNS111929. Epub 2012 Jun 15 PubMed PMID: 22702482

43. Patel KR, Shoukat S, Oliver DE, Chowdhary M, Rizzo M, Lawson DH, Khosa F, Liu Y, Khan MK. Ipilimumab and Stereotactic Radiosurgery Versus Stereotactic Radiosurgery Alone for Newly Diagnosed Melanoma Brain Metastases. Am J Clin Oncol. 2015 May 16. [Epub ahead of print] PubMed PMID 26017484

\section{Corresponding Author Wenyin Shi, MD, PhD} Department of Radiation Oncology Sidney Kimmel Medical College Thomas Jefferson University Sidney Kimmel Cancer Center at Jefferson 111 South 11th Street, Suite G301 Philadelphia, PA 19107
P: 215-955-6702
F: 215-955-0412
E: wenyin.shi@jefferson.edu 